\title{
Vascular Complications from Coronary Angiography/Percutaneous Coronary Intervention: Comparing Day Case Patients and Inpatients in a Tertiary Hospital in Thailand: A Retrospective Cohort Study
}

Chantana Charoensin, R.N. ${ }^{1}$, Ratchanee Srichai, R.N. ${ }^{1}$, Thammasin Ingviya, M.D., M.H.S., Ph.D. ${ }^{2}$

${ }^{1}$ Naradhiwas Rajanagarindra Heart Center, Faculty of Medicine, Prince of Songkla University, Songkhla 90110, Thailand.

${ }^{2}$ Department of Family and Preventive Medicine, Faculty of Medicine, Prince of Songkla University, Songkhla 90110, Thailand.

Received 17 Decemer 2019 • Revised 26 February 2020 • Accepted 4 March 2020 • Published online 5 May 2020

\begin{abstract}
:
Objective: To compare the incidence along with risk factors of vascular complications between patients having undergone Coronary angiography/Percutaneous Coronary Interventions (CAG/PCls); as day cases and those as inpatients.

Material and Methods: Our study is a retrospective cohort study. We performed a retrospective chart review of the patients, visiting a heart center of the hospital from October, 2014 to September, 2018. We included patients of a minimum 18 years of age, who had undergone CAG/PCls. Excluded patients were those who had been referred from other hospitals. The main outcomes were vascular complications defined as: (1) bleeding with significant blood loss during the procedure. (2) Hematoma within 1 month after the procedure. Wilcoxon's rank sum and chi-squared test were used to assess the risk factors.
\end{abstract}

Results: Of all 784 patients having undergone CAG/PCI, 387 were day cases and 397 were inpatients. Only 12 cases developed vascular complications. The incidence of vascular complications was not significantly different between either day case; whose incidence was 1.3\% (95\% confidence interval (Cl), 0.72-1.87), and inpatients; whose incidence was $1.8 \%(95 \% \mathrm{Cl}, 1.10-2.42)$. We found that the risk factors of vascular complications were percutaneous coronary intervention, and using a vascular closure device to remove the introducer sheath.

Conclusion: Performing CAG/PCl as day cases did not increase the risks of complications post-procedure, as compare to the inpatients. However, due to the small numbers of patients with complications future studies with more patients are needed to ensure the safety of day case CAG/PCI. Patients undergoing PCl, or patients with vascular closure devices used should be closely observed before discharge.

Keywords: cardiac catheterization, day case, percutaneous coronary intervention, vascular complications

Contact: Chantana Charoensin, R.N.

Naradhiwas Rajanagarindra Heart Center, Faculty of Medicine,

Prince of Songkla University, Songkhla 90110, Thailand.

E-mail: sachantana@gmail.com

This is an open access article under the CC BY-NC-ND license

(http://www.jhsmr.org/index.php/jhsmr/about/editorialPolicies\#openAccessPolicy).

J Health Sci Med Res 2020;38(3):203-212 doi: $10.31584 /$ jhsmr.2020739 www.jhsmr.org 


\section{Introduction}

Cardiovascular catheterization is a standard procedure for diagnosis and treatment of coronary artery disease $(C A D) .{ }^{1}$ Coronary angiography $(C A G)$ is a procedure in which the cardiac catheterization is performed with angiography, so as to obtain images of coronary arteries to confirm the diagnosis of CAD. Percutaneous coronary intervention $(\mathrm{PCl})$ is an angioplasty performed with stent implantation as a treatment for CAD. During the procedure, the introducer sheaths are placed into the femoral or radial artery as a guide for catheter insertion. Placement of the introducer sheath may cause vascular complications, including bleeding, hematoma and retroperitoneal bleeding. ${ }^{2-4}$ Most major, adverse events often occur within the first 6 hours after $\mathrm{PCl}^{5}$

In 2009, the Society for Cardiovascular Angiography and Interventions, endorsed by the American College of Cardiology Foundation, stated on their consensus documents that: after $\mathrm{PCl}$, patients could be discharged within the same calendar day after the intervention. ${ }^{6}$ After that, various studies also supported that same day discharge $\mathrm{PCls}$ or day case PCls are both feasible and safe. ${ }^{7-9}$ Day case PCls can alleviate the financial burden for patients, increase the turnover rate of hospital beds and reduce healthcare expenditures; especially in countries whose universal healthcare covers a majority of their population.

Currently, $57.0 \%$ of the British cardiologists along with $32.0 \%$ of Canadian cardiologists perform same day discharge CAG/PCls as routine practice..$^{10}$ In Thailand, the proportion of cardiologists performing day case practice has not been clearly reported. In Songklanagarind Hospital the numbers of same-day cases were 28 cases in 2009 and 177 cases in 2016.

From systematic review, a randomized control trial by Brayton et al. ${ }^{5}$, reported factors related to vascular complications were patients with hypertension, receiving dual antiplatelet, coronary intervention, receiving heparin, introducer sheath size, and use of glycoprotein IIb/lla inhibitors during the procedure. ${ }^{5}$

Although, the incidence of vascular complications after cardiac catherization were reported by studies in Thailand $^{11}$ and other countries ${ }^{12-15}$, the risk factors and criteria for selecting patients as a day case CAG/PCl has not been studied in the Thai population, and this in effect may be different from other countries. In so saying, we hypothesized vascular complications would not differ between the day case and inpatient CAG/PCI groups. Therefore, we conducted a cross sectional to objectively compare the incidence along with risk factors of vascular complications between patients having undergone CAG/ PCls, as day cases and those as inpatients.

\section{Material and Methods}

This research project has been approved by the Human Ethics Research Committee of Faculty of Medicine, Prince of Songkla University (REC. 61-021-24-7).

The study design was a retrospective cohort study. The study setting was at Naradhiwas Rajangarindra Heart Center, Songklanagarind Hospital, a tertiary hospital in southern Thailand. CAG/PCls were performed by 3 interventionists in 2 catheterization laboratory rooms at the center. A retrospective electronic chart review by purposively sampling was performed to collect demographic factors, laboratory data and clinical outcome. These were vascular complications of patients having undergone CAG/PCI, from October, 2014 to September, 2018. We included patients with a minimum of 18 years of age whom had undergone CAG/PCl. Patients, referred to and from the other hospitals were excluded. Day case patients were observed for 4 hours after sheath removal to ensure good mobility 
before discharge from the heart center. Inpatients were observed overnight before discharge from the ward. The outcomes were vascular complications defined as: (1) bleeding with significant blood loss; determined by a Hematocrit drop $>3.0 \%{ }^{16}$ and required a blood transfusion during the procedure. (2) Hematoma diameter of more than $5 \mathrm{~cm}^{17}$ Vascular complications were retrieved from the electronic medical records of Songklanagarind Hospital. The complications observed by nurses, or doctors at the inpatient department (IPD), outpatient department (OPD) or emergency room (ER) within 1 month after the procedure were noted in the case record forms.

The sample size was calculated based on the differences of two sample proportions of patients with vascular complications, between the day case and the inpatient group, assuming $z$-distribution according to Wang and Chow. ${ }^{18}$ From a meta-analysis by Brayton et al. ${ }^{5}$, the incidences of vascular complications in the day case group was $7.4 \%$; whereas, the occurrence of vascular complications in the inpatient group was $5.3 \%{ }^{5}$ Assuming alpha error of 0.05 and power of $80.0 \%$, the required sample size was 288 cases per group.

All analysis was performed in $R$ version 3.5.2 ( $R$ Core Team, Austria). Double entry was performed by two researchers who entered and examined the integrity of the data of each patient independently, if the data showed inconsistences, corrections were made for the patient records. For descriptive statistics, numbers and percentages were used to describe the categorical data. The mean, with standard deviation or median with Interquartile range $(I Q R)$, were used to describe the continuous variables, according to the distribution. To compare the characteristics as well as outcomes between the day case and inpatient groups, either Wilcoxon's test or chi-squared was used; where applicable. For subgroup analysis, we stratified and compared the patients by procedures: $\mathrm{CAG}$ and $\mathrm{PCl}$, as shown in Table 3. The p-value of chi-squared was based on Yates' continuity correction to prevent overestimation of statistical significance for small incidence of complications. ${ }^{19} \mathrm{~A}$ p-value of equal to or less than 0.05 was considered statistically significant.

\section{Results}

In total 784 patients underwent CAG/PCls, from October, 2014 to September, 2018 and were included in this study. Of the 784 patients, 387 were day cases and 397 were inpatients. Patients were predominantly male (69.8\%), and the median (IQR) age was 61 (54-70) years of age. The most common underlying diseases were hypertension (13.3\%) and dyslipidemia (12.6\%). The inpatients were older than the day case patients (62 (56-71) vs 60 (52-69) years old). Most of the inpatients (81.6\%) were taking dual anti-platelet drugs (Table 1).

In comparison to the inpatients, day case patients had a higher proportion of patients undergoing CAG $(86.0 \%$ vs $31.0 \%$, respectively, $p$-value $<0.001)$. None of the inpatients had their radial artery as the vascular access site. The proportion of 7 French. (Fr.). sheath used was slightly higher in inpatients $(3.5 \%$ vs $0.5 \%$, respectively, $\mathrm{p}$-value $=0.004$ ). Inpatients received higher doses of heparin than the day case patients $6,000(5,000-$ $6,000)$ units vs $5,000(2,500-6,000)$ units, respectively, p-value $<0.001$ (Table 2)

Of the 784 patients, $456(58.2 \%)$ patients having undergone CAG, a whole 328 (41.8\%) had undergone PCI. The common vascular access site was mainly the femoral artery (95.7\%). Introducer sheath size $6 \mathrm{Fr}$. was used in about half of the procedures. The median heparin usage were about 5,000 units. The common method for hemostasis was manual compression (88.4\%). Hemostasis methods used were not different between day cases or inpatients (Table 2). 
Table 1 Baseline characteristics

\begin{tabular}{|c|c|c|c|c|}
\hline Characteristics & Total & Inpatients & Day case & $p$-value \\
\hline \multicolumn{5}{|l|}{ Continuous variables } \\
\hline Age (yrs) [median (Q1-Q3)] & $61(54-70)$ & $62(56-71)$ & $60(52-69)$ & $0.001^{\star *}$ \\
\hline BMI $\left(\mathrm{kg} / \mathrm{m}^{2}\right)$ [median (Q1-Q3)] & $23.8(21.3-26.7)$ & $24.1(21.8-27.0)$ & $23.6(21.0-26.5)$ & $0.106^{\star \star}$ \\
\hline Total $[n(\%)]$ & $784(100.0)$ & $397(50.6)$ & $387(49.4)$ & \\
\hline Sex & & & & $0.243^{*}$ \\
\hline Male & $547(69.8)$ & $285(71.8)$ & $262(67.7)$ & \\
\hline \multicolumn{5}{|l|}{ Underlying disease } \\
\hline No known underlying disease & $321(40.9)$ & $162(40.8)$ & $159(41.1)$ & $0.995^{\star}$ \\
\hline \multicolumn{5}{|l|}{ Only one disease } \\
\hline $\mathrm{DM}$ & $28(3.6)$ & $17(7.2)$ & $11(4.8)$ & $0.372^{*}$ \\
\hline $\mathrm{HT}$ & $104(13.3)$ & $51(12.8)$ & $53(13.7)$ & $0.806^{*}$ \\
\hline DLP & $99(12.6)$ & $36(9.1)$ & $63(16.3)$ & $0.003^{*}$ \\
\hline \multicolumn{5}{|l|}{ Two or more diseases } \\
\hline $\mathrm{DM}+\mathrm{HT}$ & $54(6.9)$ & $27(6.8)$ & $27(7.0)$ & $1.000^{*}$ \\
\hline HT+DLP & $103(13.1)$ & $65(16.4)$ & $38(9.8)$ & $0.009^{*}$ \\
\hline$D M+D L P$ & $12(1.5)$ & $2(0.5)$ & $10(2.6)$ & $0.037^{*}$ \\
\hline $\mathrm{DM}+\mathrm{HT}+\mathrm{DLP}$ & $63(8.0)$ & $37(9.3)$ & $26(6.7)$ & $0.230^{*}$ \\
\hline \multicolumn{5}{|l|}{ History of anticoagulant uses } \\
\hline No anticoagulant & $69(8.8)$ & $18(4.5)$ & $51(13.2)$ & $<0.001^{*}$ \\
\hline ASA & $88(11.2)$ & $34(8.6)$ & $54(14.0)$ & $0.023^{*}$ \\
\hline P2Y12 & $8(1.0)$ & $4(0.1)$ & $4(0.1)$ & $1.000^{*}$ \\
\hline DAPT (ASA+P2Y12) & $522(66.6)$ & $324(81.6)$ & $198(51.2)$ & $<0.001^{\star}$ \\
\hline Warfarin & $74(9.4)$ & $14(3.5)$ & $60(15.5)$ & $<0.001^{*}$ \\
\hline ASA+warfarin & $13(1.7)$ & $2(0.2)$ & $11(2.8)$ & $0.022^{*}$ \\
\hline P2Y12+warfarin & $1(0.1)$ & $1(0.3)$ & $0(0.0)$ & $1.000^{*}$ \\
\hline DAPT+warfarin & $9(1.1)$ & $0(0.0)$ & $9(2.3)$ & $0.006^{*}$ \\
\hline
\end{tabular}

$B M l=$ body mass index, $Q 1=1^{\text {st }}$ quartile, $Q 3=3^{\text {rd }}$ quartile, $\mathrm{kg} / \mathrm{m}^{2}=\mathrm{kilogram}$ per square meter, $\mathrm{DM}=$ diabetes mellitus, $\mathrm{HT}=\mathrm{essential}$ hypertension, DLP=dyslipidemia, ASA=aspirin; P2Y12=P2Y12 receptor antagonist, DAPT=dual antiplatelet rherapy ${ }^{*} X^{2}$ test ${ }^{* *}$ Wilcoxon's rank sum test

Table 2 Distribution of patients by procedural characteristics

\begin{tabular}{|c|c|c|c|c|}
\hline Procedural factors & $\begin{array}{l}\text { Total } \\
\text { Number (\%) }\end{array}$ & $\begin{array}{l}\text { Inpatients } \\
\text { Number (\%) }\end{array}$ & $\begin{array}{l}\text { Day case } \\
\text { Number (\%) }\end{array}$ & $p$-value \\
\hline Total & $784(100.0)$ & $397(50.6)$ & $387(49.4)$ & \\
\hline Procedure & & & & $<0.001^{*}$ \\
\hline CAG & $456(58.2)$ & $123(31.0)$ & $333(86.0)$ & \\
\hline $\mathrm{PCl}$ & $328(41.8)$ & $274(69.0)$ & $54(14.0)$ & \\
\hline Vascular access site & & & & $<0.001^{*}$ \\
\hline Femoral artery & $750(95.7)$ & $397(100.0)$ & $353(91.2)$ & \\
\hline Radial artery & $34(4.3)$ & $0(0.0)$ & $34(8.8)$ & \\
\hline \multicolumn{5}{|l|}{ Sheath size } \\
\hline Sheath $5 \mathrm{Fr}$. & 331 (42.2) & $150(37.8)$ & $181(46.8)$ & $0.013^{*}$ \\
\hline Sheath 6 Fr. & $436(55.6)$ & $232(58.4)$ & $204(52.7)$ & $0.123^{*}$ \\
\hline Sheath $7 \mathrm{Fr}$. & $17(2.2)$ & $15(3.5)$ & $2(0.5)$ & $0.004^{*}$ \\
\hline
\end{tabular}


Table 2 (continued)

\begin{tabular}{|c|c|c|c|c|}
\hline Procedural factors & $\begin{array}{l}\text { Total } \\
\text { Number }(\%)\end{array}$ & $\begin{array}{l}\text { Inpatients } \\
\text { Number (\%) }\end{array}$ & $\begin{array}{l}\text { Day case } \\
\text { Number }(\%)\end{array}$ & $\mathrm{p}$-value \\
\hline Heparin (units) [median (Q1-Q3)] & $\begin{array}{l}5,000 \\
(5,000-6,000)\end{array}$ & $\begin{array}{l}6,000 \\
(5,000-6,000)\end{array}$ & $\begin{array}{l}5,000 \\
(2,500-6,000)\end{array}$ & $<0.001^{\star *}$ \\
\hline \multicolumn{5}{|l|}{ Blood pressure during procedure } \\
\hline SBP (mmHg) [median (Q1-Q3)] & $141(126-161)$ & $144(129-165)$ & $138(123-155)$ & $<0.001^{\star *}$ \\
\hline DBP (mmHg) [median (Q1-Q3)] & $82(73.0-90.5)$ & $82.5(74.0-91.0)$ & $80(72.0-90.0)$ & $0.036^{* *}$ \\
\hline Hemostasis method after sheath removal & & & & $0.928^{*}$ \\
\hline Manual compression & $693(88.4)$ & 366 (92.2) & 327 (92.6) & \\
\hline Vascular closure device (proglide $^{\circledR}$ ) & $57(7.3)$ & $31(7.8)$ & $26(7.4)$ & \\
\hline $\begin{array}{l}\text { Vascular compression device (TR band }{ }^{\boxplus} \text { in transradial } \\
\text { accessed sited) }\end{array}$ & $34(4.3)$ & $0(0.0)$ & $34(100.0)$ & \\
\hline Vascular complications & $12(1.5)$ & $7(1.8)$ & $5(1.3)$ & \\
\hline Bleeding & $6(0.8)$ & $5(1.3)$ & $1(0.3)$ & $0.231^{*}$ \\
\hline Hematoma & $6(0.8)$ & $2(0.5)$ & $4(1.0)$ & $0.659^{*}$ \\
\hline
\end{tabular}

$C A G=$ percutaneous transluminal coronary angiography, $P C l=$ percutaneous coronary intervention; Fr. $=$ french; $Q 1=1^{\text {st }}$ quartile, $Q 3=3^{\text {rd }}$ quartile, $\mathrm{SBP}=$ systolic blood pressure; $\mathrm{DBP}=$ diastolic blood pressure; $\mathrm{mmHg}$ = millimeters of mercury; $\mathrm{p}$-value= probability value ${ }^{*} X^{2}$ test ${ }^{* *}$ Wilcoxon's rank sum tes

For either day case patients or inpatients, patients who underwent $\mathrm{PCl}$ used a sheath size of 7 French, while none undergoing CAG used. Patients who underwent $\mathrm{PCl}$, in both groups, received median (Q1-Q3) amounts of heparin at 6,000 $(5,000-6,000)$ units; while for patients undergoing CAG received the median (Q1-Q3) amounts of heparin, at 0 units in the inpatient group, and 2,000 $(2,000-3,000)$ units. For the inpatient subgroup, patients undergoing CAG had slightly higher systolic blood pressure (SBP) and diastolic blood pressure (DBP) than patients undergoing $\mathrm{PCl}$ ( $p$-value=0.003). Despite not being statistically significant, the patients who underwent $\mathrm{PCl}$ showed slightly higher incidence of vascular complications; including bleeding and hematoma, than patients having undergone CAG (Table 3).

Only 12 patients had vascular complications, 6 patients had access site bleeding; while another 6 patients had access site hematoma within a month. The incidence of vascular complications did not differ between the day case group $(1.30 \%, 95 \%$ confidence interval $(\mathrm{Cl})$ : $0.72-$ $1.87)$ or inpatients $(1.80 \%, 95 \% \mathrm{Cl}: 1.10-2.42)$. Vascular complications were related to $\mathrm{PCl}$, and the hemostasis method after sheath removal. Vascular complications occurred more frequently in patients who underwent $\mathrm{PCl}$ than those who underwent CAG $(2.7 \%$ vs $0.7 \%$, p-value $=0.040)$. Using Proglide ${ }^{\circledR}$ [Abbott, The United State of America (USA)], a vascular closure device, as a hemostasis method after sheath removal, had a higher chance of vascular complication occurrence, than those performed via manual compression ( $10.5 \%$ vs $0.9 \%$, p-value<0.001) (Table 4). However, there were no serious vascular complications. Underlying diseases, SBP, DBP, vascular access site, history of anticoagulant uses were not related to vascular complications (Table 4). 


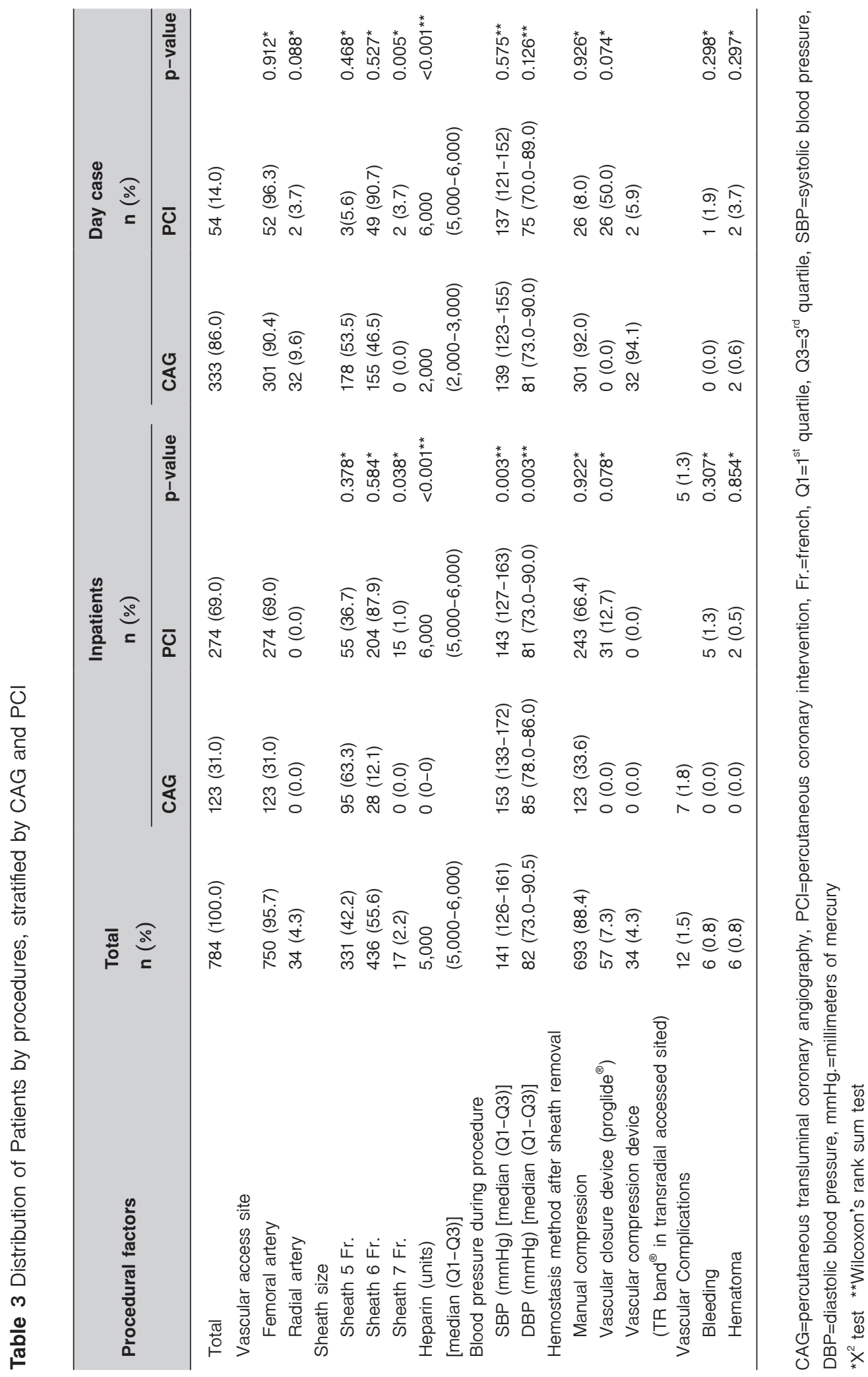


Table 4 Procedure and characteristics of patients with vascular complications

\begin{tabular}{|c|c|c|c|c|}
\hline Vascular complication & $\begin{array}{l}\text { Total } \\
(n=784)\end{array}$ & $\begin{array}{l}\text { Yes } \\
(n=12)\end{array}$ & $\begin{array}{l}\text { No } \\
(n=772)\end{array}$ & $p$-value \\
\hline Courses of treatments & & & & $0.805^{\star}$ \\
\hline Day case & $387(49.4)$ & $5(1.3)$ & $382(98.7)$ & \\
\hline Admit & $397(50.6)$ & $7(1.8)$ & $390(98.2)$ & \\
\hline \multicolumn{5}{|l|}{ Patients characteristics } \\
\hline Sex & & & & $1.000^{*}$ \\
\hline Male & $547(69.8)$ & $8(1.5)$ & $539(98.5)$ & \\
\hline Age (yrs) [median (Q1-Q3)] & $61(54.0-70.0)$ & $54(50.0-67.6)$ & $61(54.0-70.0)$ & $0.207^{\star \star}$ \\
\hline $\mathrm{BMI}$ & $23.8(21.3-26.7)$ & $23.2(21.1-24.1)$ & $23.8(21.3-26.7)$ & $0.309^{* *}$ \\
\hline \multicolumn{5}{|l|}{ Underlying disease } \\
\hline No Known underlying disease & $321(40.9)$ & $4(1.2)$ & $317(98.8)$ & $0.807^{*}$ \\
\hline $\mathrm{DM}$ & $28(3.6)$ & $0(0.0)$ & $28(100.0)$ & $1.000^{*}$ \\
\hline $\mathrm{HT}$ & $104(13.3)$ & $3(2.9)$ & $101(97.1)$ & $0.548^{*}$ \\
\hline DLP & $99(12.6)$ & $2(2.0)$ & $97(98.0)$ & $1.000^{*}$ \\
\hline $\mathrm{DM}+\mathrm{HT}$ & $54(6.9)$ & $0(0.0)$ & $54(100.0)$ & $0.708^{*}$ \\
\hline DM+DLP & $12(1.5)$ & $0(0.0)$ & $12(100.0)$ & $1.000^{*}$ \\
\hline $\mathrm{HT}+\mathrm{DLP}$ & $103(13.1)$ & $2(1.9)$ & $101(98.1)$ & $1.000^{*}$ \\
\hline $\mathrm{DM}+\mathrm{HT}+\mathrm{DLP}$ & $63(8.0)$ & $1(1.6)$ & $62(98.4)$ & $1.000^{*}$ \\
\hline Procedure & & & & $0.040^{*}$ \\
\hline CAG & $456(58.2)$ & $3(0.7)$ & $453(99.3)$ & \\
\hline $\mathrm{PCl}$ & $328(41.8)$ & $9(2.7)$ & $319(97.3)$ & \\
\hline Vascular access site & & & & $1.000^{*}$ \\
\hline Femoral & $750(95.7)$ & $12(1.6)$ & $738(98.4)$ & \\
\hline Radial & $34(4.3)$ & $0(0.0)$ & $34(100.0)$ & \\
\hline \multicolumn{5}{|l|}{ Sheath size } \\
\hline Sheath $5 \mathrm{Fr}$. & $331(42.2)$ & $3(25.0)$ & $328(42.5)$ & $0.356^{*}$ \\
\hline Sheath 6 Fr. & $436(55.6)$ & $8(66.7)$ & $428(55.4)$ & $0.628^{*}$ \\
\hline Sheath 7 Fr. & $17(2.2)$ & $1(8.3)$ & $16(2.1)$ & $0.632^{*}$ \\
\hline Heparin (units) & 5,000 & 6,000 & 5,000 & $0.208^{*}$ \\
\hline (median (Q1-Q3)) & $(5,000-6,000)$ & $(6,000-6,000)$ & $(5,000-6,000)$ & \\
\hline SBP (mmHg.) [median (Q1-Q3)] & $141(126.0-161.0)$ & $147(131.0-155.0)$ & $141(126.0-162.0)$ & $0.799^{* *}$ \\
\hline DBP (mmHg.) [median (Q1-Q3)] & $82(73.0-90.5)$ & $89(82.0-93.0)$ & $81(73.0-90.0)$ & $0.190^{\star \star}$ \\
\hline Hemostasis method after sheath removal & & & & $<0.001^{*}$ \\
\hline Manual compression & $693(88.4)$ & $6(0.9)$ & $687(99.1)$ & \\
\hline Vascular closure device (proglide $^{\circledast}$ ) & $57(7.3)$ & $6(10.5)$ & $51(89.5)$ & \\
\hline
\end{tabular}

yrs=years, $Q 1=1^{\text {st }}$ quartile, $Q 3=3^{\text {rd }}$ quartile, $B M l=$ body mass index, $D M=$ diabetes mellitus; $H T=e s s e n t i a l$ hypertension, $D L P=d y s l i p i d e m i a$, $\mathrm{CAG}=$ percutaneous transluminal coronary angiography, $\mathrm{PCl}=$ percutaneous coronary intervention, $\mathrm{Fr} .=$ french, $\mathrm{SBP}=$ systolic blood pressure, $\mathrm{DBP}=$ diastolic blood pressure; $\mathrm{mmHg} .=$ millimeters of mercury

${ }^{*}{ }^{2}$ test ${ }^{* *}$ Wilcoxon's rank sum test 


\section{Discussion}

This study supported that: day case CAG/PCI was as safe as inpatient CAG/PCl. Only 12 cases developed vascular complications. The proportion of patients with vascular complications did not differ significantly between the day case group $(1.3 \%, 95 \% \mathrm{Cl}$ : $0.72-1.87)$ and inpatient group $(1.8 \%, 95 \% \mathrm{Cl}: 1.10-2.42)$. Associated factors with the occurrence of vascular complications were: coronary interventions and hemostasis, with vascular closure devices used.

The incidence of vascular complications in our study was low (about 1.3\% and 1.8\%) in both day cases and inpatient groups. The systematic review, from a randomized control trial by Brayton et al. $^{5}$, reported similar numbers of incidence. The same study also reported that: the vascular complications of the patients after CAG/PCI were not different between day case patients and inpatients. ${ }^{5}$ Similar studies by Shoff et al, Abdelaal et al. and Koch also found similar results, in that the complications were low in both patient groups. ${ }^{8,20,21}$ Brayton et al. found that patients with hypertension, receiving dual antiplatelet drugs, coronary interventions, receiving heparin, introducer sheath size and use of Glycoprotein IIb/lla inhibitors during the procedure were related to vascular complications. ${ }^{5}$ Our research did not find any relationship between these factors and vascular complications; with the exception of coronary interventions and the vascular closure device used.

A possible explanation for the relationship between coronary intervention and vascular complications might be procedural factors. In our subgroup analysis stratifying patients undergoing $\mathrm{CAG}$ or $\mathrm{PCl}$, the patients having undergone $\mathrm{PCl}$ received higher doses of Heparin, additionally the size of the sheath used were generally larger than the patients undergoing CAG (Table 3). Therefore, those factors might explain why patients undergoing coronary intervention had higher incidence of vascular complications.
Using a vascular closure device (Proglide ${ }^{\circledR}$ (Abbott, USA)), as the homeostasis after the CAG/PCI, increased the risk of vascular complications, when compared to manual compression. Manual compression has been the conventional method for hemostasis after sheath removal for the femoral artery access site since $1953 .^{22}$ Various studies have shown that vascular closure devices were effective for stopping bleeding after cardiovascular procedures. $^{22,23}$ Studies also reported that suture mediated vascular closure devices have a similar numbers of patients with complications as that of manual compression. ${ }^{15,24}$ These devices are used to reduce the waiting time in mobilizing patients; however, compared to using the device, as a homeostasis, manual compressions are cheaper and do not require special equipment. ${ }^{25,26}$ In contrast to these studies, we found that vascular complications were higher in patients who used vascular closure devices. This might be due to the lack of skills and inexperience of healthcare personal. The device has been available, but has only been utilized for only about 2 years in the heart center before the data collection of this study.

From our reviews, this study is the first study to examine complications of day case CAG/PCI in Thailand, as well as which the sample size was relatively large, compared to other studies in Thailand. However, due to its retrospective design, confounding factors by indication, such as only low risk case being selected for the day case patients could not be avoided. In addition, the number of patients with vascular complications was small, so we could not perform multivariate regression analysis to assess the relationship between associate factors with the occurrence of vascular complications while controlling for confounders. Therefore, our result should be interpreted with caution, due to the above mentioned limitations.

Nevertheless, this study shows that the incidences of vascular complications in the day case group were as low as those in the inpatient group. ${ }^{8}$ Hence, CAG/PCI can 
be performed as a day case procedure in selective patients safely, without the added risks of vascular complications.

\section{Conclusion}

Day case CAG/PCl can be performed with a low risk of vascular complications. CAG/PCls should be performed as day cases, so as to reduce the expenditures for patients, increase hospital bed turnover rates and reduce the reimbursements from universal healthcare coverage of the Ministry of Health. However, patients undergoing $\mathrm{PCl}$, and using vascular closure devices should be closely observed before discharge.

\section{Acknowledgement}

The authors would like to thank the Naradhiwas Rajanagarindra Heart Center, Songklanagarind Hospital for their support of data collection.

\section{Funding sources}

Thai Health Promotion Foundation.

\section{Conflict of Interest}

None declared.

\section{References}

1. Alpert JS, Thygesen K, Antman E, Bassand JP. Myocardial infarction redefined--a consensus document of The Joint European Society of Cardiology/American College of Cardiology Committee for the redefinition of myocardial infarction. J Am Coll Cardiol 2000;36:959-69.

2. Baim DS, Grossman W. Complications. In: Baim DS, Grossman W, editors. Grossman's cardiac catheterization. $8^{\text {th }}$ ed. Philadelphia: Lippincott Williums and Wilkins; 2000;p.65.

3. Muthusamy P, Busman DK, Davis AT, Wohns DH. Assessment of clinical outcomes related to early discharge after elective percutaneous coronary intervention: COED PCI. Catheter Cardiovasc Interv Off J Soc Card Angiogr Interv 2013;81:6-13.

4. Rao SV, Kaltenbach LA, Weintraub WS, Roe MT, Brindis RG, Rumsfeld JS, et al. Prevalence and outcomes of same- day discharge after elective percutaneous coronary intervention among older patients. JAMA 2011;306:1461-7.

5. Brayton KM, Patel VG, Stave C, de Lemos JA, Kumbhani DJ. Same-day discharge after percutaneous coronary intervention: a meta-analysis. J Am Coll Cardiol 2013;62:275-85.

6. Chambers CE, Dehmer GJ, Cox DA, Harrington RA, Babb JD, Popma JJ, et al. Defining the length of stay following percutaneous coronary intervention: an expert consensus document from the Society for Cardiovascular Angiography and Interventions. Endorsed by the American College of Cardiology Foundation. Catheter Cardiovasc Interv 2009; 73:847-58.

7. Ramharrack DV, Jurgens CY, Shlofmitz RA. Phenotype of same-day-discharge patients after percutaneous coronary intervention. J Cardiovasc Nurs 2018;33:160-7.

8. Shroff A, Kupfer J, Gilchrist IC, Caputo R, Speiser B, Bertrand $\mathrm{OF}$, et al. Same-day discharge after percutaneous coronary intervention: current perspectives and strategies for mmplementation. JAMA Cardiol 2016;1:216-23.

9. Bundhun PK, Soogund MZS, Huang W-Q. Same day discharge versus overnight stay in the hospital following percutaneous coronary intervention in patients with stable coronary artery disease: a systematic review and meta-analysis of randomized controlled trials. PLOS ONE 2017;12:e0169807

10. Seto AH, Shroff A, Abu-Fadel M, Blankenship JC, Boudoulas $\mathrm{KD}$, Cigarroa JE, et al. Length of stay following percutaneous coronary intervention: an expert consensus document update from the society for cardiovascular angiography and interventions. Catheter Cardiovasc Interv 2018;92:717-31.

11. Supa J, Ratchanee N. Factors related to the occurrence of vascular complications among patients receiving percutaneous coronary Interventions via the Femoral Artery. APHEIT J 2017;6:14-24.

12. Applegate RJ, Grabarczyk MA, Little WC, Craven T, Walkup $\mathrm{M}$, Kahl FR, et al. Vascular closure devices in patients treated with anticoagulation and iib/iiia receptor inhibitors during percutaneous revascularization. J Am Coll Cardiol 2002;40:78-83.

13. Christensen BV, Manion RV, lacarella CL, Meyer SM, Cartland JL, Bruhn-Ding BJ, et al. Vascular complications after angiography with and without the use of sandbags. Nurs Res 1998;47:51-3.

14. Dangas G, Mehran R, Kokolis S, Feldman D, Satler LF, 
Pichard AD, et al. Vascular complications after percutaneous coronary interventions following hemostasis with manual compression versus arteriotomy closure devices. J Am Coll Cardiol 2001;38:638-41.

15. Nikolsky E, Mehran R, Halkin A, Aymong ED, Mintz GS, Lasic Z, et al. Vascular complications associated with arteriotomy closure devices in patients undergoing percutaneous coronary procedures. J Am Coll Cardiol 2004;44:1200-9.

16. Elzik ME, Dirschl DR, Dahners LE. Correlation of transfusion volume to change in hematocrit. Am J Hematol 2006;81: 145-6.

17. Al Sadi AKA, Omeish AFY, Al-Zaru IM. Timing and predictors of femoral haematoma development after manual compression of femoral access sites. JPMA J Pak Med Assoc 2010;60: 620-5.

18. Shao J, Chow SC, Wang H. Sample size calculations in clinical research. $2^{\text {nd }}$ ed. Florida: CRC Press; 2003.

19. Yates F. Contingency table involving small numbers and the $\chi 2$ test. J R Stat Soc 1934;(Suppl 1):S217-35.

20. Abdelaal E, Rao SV, Gilchrist IC, Bernat I, Shroff A, Caputo R, et al. Same-day discharge compared with overnight hospitalization after uncomplicated percutaneous coronary intervention: a systematic review and meta-analysis. JACC Cardiovasc Interv 2013;6:99-112.
21. Koch KT, Piek JJ, Winter RJ de, David GK, Mulder K, Lie $\mathrm{KI}$. Short-term (4 Hours) observation after elective coronary angioplasty. Am J Cardiol 1997;80:1591-4.

22. Jones $T$, McCutcheon $H$. A randomised controlled trial comparing the use of manual versus mechanical compression to obtain haemostasis following coronary angiography. Intensive Crit Care Nurs 2003;19:11-20.

23. Lehmann KG, Heath-Lange SJ, Ferris ST. Randomized comparison of hemostasis techniques after invasive cardiovascular procedures. Am Heart J 1999;138:1118-25.

24. Sekhar A, Sutton BS, Raheja P, Mohsen A, Anggelis E, Anggelis $\mathrm{CN}$, et al. Femoral arterial closure using ProGlide ${ }^{\circledR}$ is more efficacious and cost-effective when ambulating early following cardiac catheterization. Int $\mathrm{J}$ Cardiol Heart Vasc 2016;13:6-13.

25. Capasso VA, Codner C, Nuzzo-Meuller G, Cox EM, Bouvier $S$. Peripheral arterial sheath removal program: a performance improvement initiative. J Vasc Nurs 2006;24:127-32.

26. Walker SB, Cleary S, Higgins M. Comparison of the Femo Stop device and manual pressure in reducing groin puncture site complications following coronary angioplasty and coronary stent placement. Int J Nurs Pract 2001;7:366-75. 